\title{
Innovación tecnológica,
} procesos de aprendizaje

\section{y evaluación en la enseñanza de la restauración}

Alejandro Acosta Collazo / Edith Hernández López.

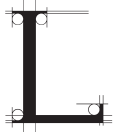

as escuelas tradicionales de conservación de monumentos históricos en México procuran la enseñanza de materias prácticas que complementan sus planes de estudio. El afamado arquitecto historiador Carlos Chanfón Olmos reflexiona tenazmente en torno a la cristalización de la teoría restauratoria, complementada con una enseñanza-aprendizaje basada en la praxis. Así lo demuestran sus tratados relacionados con el manejo del elemento constructivo por excelencia en el monumento edificado: la piedra labrada, que en su correcta interpretación y pericia en su manufactura se conoce como "estereotomía".

Para asimilar el trabajo de estereotomía, el alarife se ocupaba constantemente en una praxis que se convertía en ocasiones en la producción de obras maestras, basadas en el corte adecuado de la piedra de cantera. La interpretación en tres dimensiones de la piedra, combinada con un correcto entendimiento de la lógica mecánica-constructiva de los edificios, permitía que el "cantero" se convirtiera en el artífice central en la producción de espacios habitables relevantes construidos a mano.

Los sistemas digitales, en la actualidad, han demostrado ser una herramienta poderosa en el entendimiento de los espacios históricos edificados. El arquitecto utiliza este valioso instrumento para vender también sus productos de diseño en el mercado; de modo que la formación apoyada en los elementos digitales es obligada en las escuelas de educación superior en nuestros días.

Se aplicó, con fines académicos en este estudio de caso, una metodología basada en los procesos relativos al trazo, corte, ensamblado, lógica constructiva, cargas de la edificación, dimensiones, tipos de piedra, alternativas de funcionamiento y construcción a escala de un "arco" de algún edificio histórico. La muestra seleccionada la conformó un grupo de alumnos de la Licenciatura en Diseño de Interiores de la UAA, dentro de la materia: Optativa Profesionalizante III "Restauración", en el semestre enero-junio de 2011. Esta teoría sirvió como fundamento en la presentación del tema del "arco". Después de ver y analizar el video: The Royal Saltworks of Arc-et-Senans (Copans, 2005), de Claude Nicolas Ledeoux, basado en el desglose sistemático de la estereotomía de un edificio en particular; resultó de peculiar interés al 
mostrar el derrumbe paulatino de un edificio de piedra, la recuperación de las piezas y la práctica de una adecuada "anastilosis", los estudiantes mostraron un interés especial por el funcionamiento de elementos constructivos como el "arco" y la "columna". A pesar de la inexistencia de acercamiento físico al inmueble, la explicación digital otorgó a los alumnos una mejor aprehensión del tema y el entendimiento del funcionamiento mecánico-constructivo de este tipo de espacios habitables. Este caso de recuperación perceptiva se complementó con preguntas y afirmaciones en la retroalimentación del tema. Los alumnos comprendieron de esta manera el proceso constructivo de un edificio histórico; lo cual es fundamental para el entendimiento de la estereotomía.

La evaluación de la primera parte del proceso de aprendizaje se llevó a cabo por medio de preguntas concretas a los alumnos; asimismo, su tarea era buscar un arco que sirviese de modelo, dibujarlo y entregarlo en formato digital como imagen. La segunda parte del proceso implicó realizar en clase (sobre su imagen de "arco" impresa) el trazo regulador de diseño y la identificación del tipo de "arco", según la base teórica expuesta por el profesor; esto implicó trabajar también con regla y compás, para así obtener una plantilla de trabajo del "arco" seleccionado, con la supervisión y evaluación constante del facilitador. La tercera etapa consistió en la fabricación a escala del "arco", en forma individual. En principio, se pensó en utilizar piedra de cantera y hacer que un cantero realizara los modelos a escala; sin embargo, esto restaba créditos a la autoría del trabajo y el proceso de evaluación presentaría obstáculos epistemológicos, aunado al costo del ejercicio académico.

Se optó por trabajar con un material noble, sugerido y utilizado por los mismos alumnos en las áreas de diseño: un aglomerado con fibras de madera de densidad media (conocido en el mercado como MDF). Este material permite amoldar convenientemente formas para la construcción de maquetas. El espesor del MDF también presentaba una limitante y se optó por utilizar tres capas adheridas entre sí para dar una apariencia más real a escala, comparado con la estereotomía de las piedras utilizadas en la realidad para construir un "arco". Las escalas que se manejaron fueron entre 1:10 y 1:20; es decir, entre 10 y 20 veces más pequeño que lo real. En esta etapa, el ingenio para resolver el material de manufactura a escala también fue objeto de evaluación. Una vez adheridas las capas de MDF se procedió a realizar una calca del trazo del "arco" y se utilizó un sistema innovador en términos tecnológicos, de corte con sistema láser asistido por computadora, para realizar el moldeo del material. La condicionante en este último proceso de evaluación era que el arco a escala se sostuviera por sí mismo. Es conveniente mencionar que de las diez propuestas evaluadas, $100 \%$ se sostuvieron en pie. Al carecer de cimbra, como normalmente se acostumbraba en la manufactura real de "arcos" de piedra, los alumnos sostenían manualmente el modelo a escala, colocando sistemáticamente las dovelas (numeradas), pieza por pieza, hasta colocar la piedra "clave". Precisamente, parte de la evaluación incluía el entendimiento por parte de los alumnos de la colocación y función de esta pieza fundamental en el trabajo mecánicoconstructivo del "arco" pues, sin esta piedra, no se sostiene por sí mismo. Desde luego, la complejidad del "arco" y el número de dovelas tenía que ver con el ensamblaje final.

\section{Conclusiones}

El proceso de aprendizaje en el ejemplo en cuestión se basó en la innovación tecnológica y digital. La forma de evaluación practicada no está basada en un instrumento final. La evaluación se llevó a cabo en forma sistemática y dialéctica durante todo el ejercicio, lo que dio como resultado una evaluación sustantiva del proceso y no solamente un instrumento global, sin tomar en cuenta el esfuerzo del aprendizaje, incluyendo caídas y recuperación del rumbo en el objeto de estudio. La emoción de los alumnos se vio reflejada cuando el arco manufacturado a escala se mantuvo en pie, el principal logro en el ejercicio. Si el arco se mantiene en pie y sin el desfase de las dovelas, esto se traduce en una estereotomía perfectamente aplicada.

El resultado final fue altamente favorable, combinando teoría y práctica; aunado a la supervisión constante del facilitador del aprendizaje. El alumno se tornó en un ente participante y atraído por un método de trabajo novedoso en la didáctica contemporánea, con espacios temporales para la reflexión, considerando que las unidades de trabajo provenían 
de elementos históricos. Es importante indicar que este aprendizaje (y su práctica en general) coadyuva a la adquisición de conocimientos con medidas y proporciones reales que otorga al alumno mayor seguridad cuando se encuentra en una situación similar en su vida profesional.

Figura 1. La evaluación de todo el proceso es más importante que un instrumento final de evaluación.

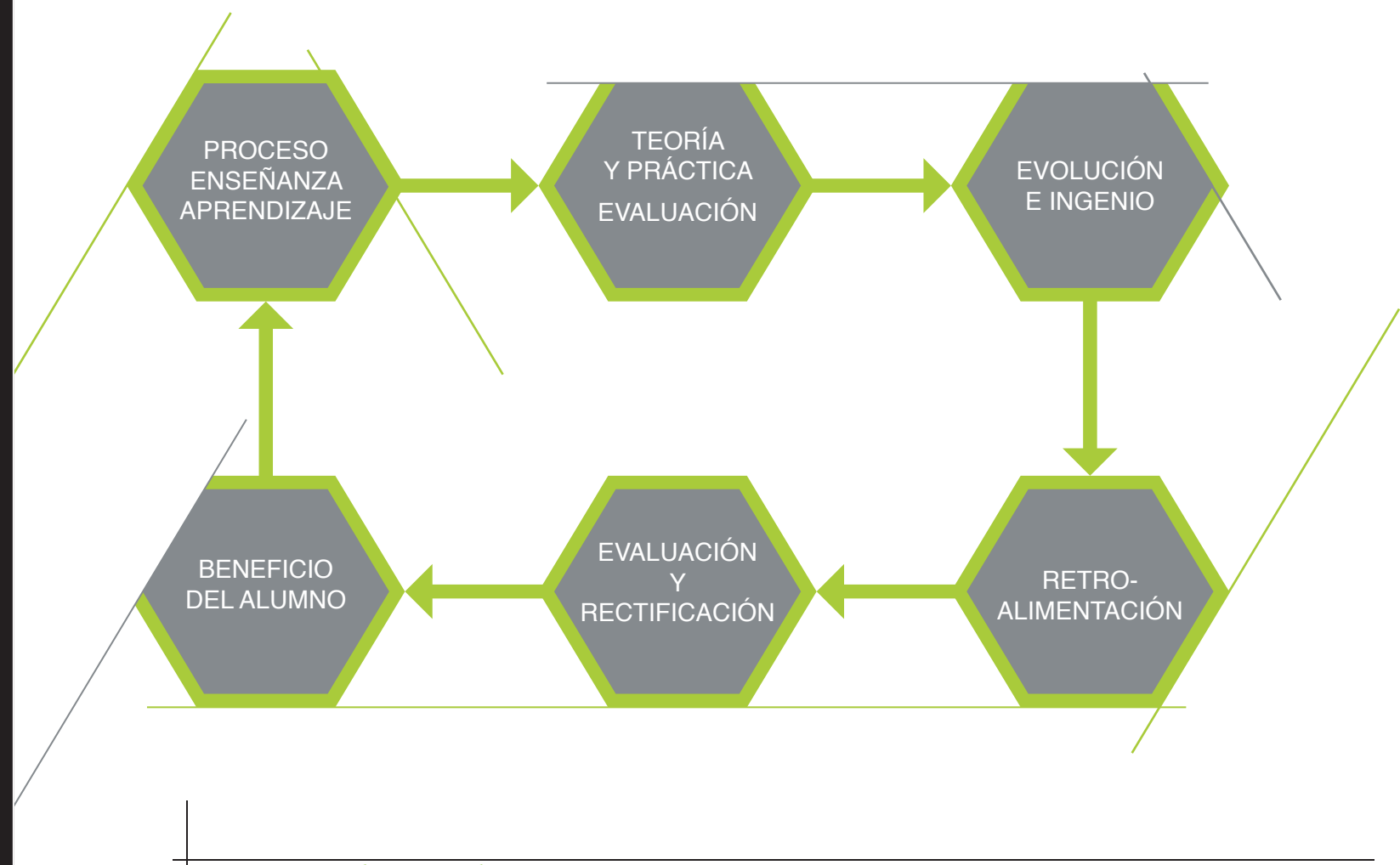

Fuentes de consulta

Blanco Gutiérrez, O. (2004). NUT-ULA. Tendencias en la evaluación de los aprendizajes. En Revista de Teoría y Didáctica de las Ciencias Sociales. Enero-diciembre, núm. 009, pp. 111-130.

Copans, R. y Neumann, S. (2005). The Royal Saltworks of Arc-et-Senans en Architectures 4, Arte Video/Facets video/Reunion des Musées Nationaux. Chanfón Olmos, C. (1990). Curso de estereotomía: procedimientos de trazo para materiales pétreos. Mérida, México: Unidad de Postgrado e Investigación de la Facultad de Arquitectura, Ediciones de la Universidad Autónoma de Yucatán, (Cuadernos de Material Didáctico 1).

(1972). La estereotomía, una ciencia injustamente olvidada. México: INAH, Boletín 1.

Díaz Barriga, Á. (2008). Didáctica y currículum. México: Paidós Educador. Secretaría del Patrimonio Nacional. (1975). Vocabulario Arquitectónico Ilustrado. México.

Tejada, F.J. (1999). La evaluación: su conceptualización. En: Jiménez, B., Evaluación de programas, centros y profesores. Madrid, España: Síntesis, pp. 25-55. 